\title{
Expressed wishes and incidence of euthanasia in advanced lung cancer
} patients

\begin{abstract}
Koen Pardon*, Reginald Deschepper*, Robert Vander Stichele,*, Jan L. Bernheim*, Freddy Mortier*, , Denis Schallier ${ }^{+}$, Paul Germonpré ${ }^{\S}$, Daniella Galdermans ${ }^{f}$, Willem Van Kerckhoven** and Luc Deliens" ${ }^{\star * \#}$ on behalf of the EOLIC-consortium "ब
\end{abstract}

ABSTRACT: This study explores expressed wishes and requests for euthanasia (i.e. administration of lethal drugs at the explicit request of the patient), and incidence of end-of-life decisions with possible life-shortening effects (ELDs) in advanced lung cancer patients in Flanders, Belgium.

We performed a prospective, longitudinal, observational study of a consecutive sample of advanced lung cancer patients and selected those who died within 18 months of diagnosis. Immediately after death, the pulmonologist/oncologist and general practitioner (GP) of the patient filled in a questionnaire. Information was available for 105 out of 115 deaths.

According to the specialist or GP, one in five patients had expressed a wish for euthanasia; and three in four of these had made an explicit and repeated request. One in two of these received euthanasia. Of the patients who had expressed a wish for euthanasia but had not made an explicit and repeated request, none received euthanasia. Patients with a palliative treatment goal at inclusion were more likely to receive euthanasia. Death was preceded by an ELD in $62.9 \%$ of patients.

To conclude, advanced lung cancer patients who expressed a euthanasia wish were often determined. Euthanasia was performed significantly more among patients whose treatment goal after diagnosis was exclusively palliative.

KEYWORDS: End-of-life decisions, nonsmall cell lung cancer, palliative care

$\mathbf{A}$ 11 over the world, physicians receive requests for euthanasia from seriously ill patients and sometimes accede to these requests [1-5]. However, euthanasia is only legally permitted, under well-defined conditions, in three European countries: Belgium, the Netherlands and Luxembourg [6-8]. The principal conditions that are laid down in the euthanasia law in these countries are that 1 ) the patient must be in a condition of constant and unbearable physical and/or mental suffering caused by illness or accident, with no possibility of improvement and 2) the request must be made voluntarily and be well considered and repeated.

Several nationwide population studies in Flanders (Belgium) and the Netherlands have determined the incidence of euthanasia and other end-of-life decisions with possible or certain life-shortening effects (ELDs) $[2,9,10]$. These studies have never been disease specific, nor have they qualified more in depth the process leading towards euthanasia. This study focuses on advanced lung cancer patients and studies in depth the process leading to euthanasia, the most controversial of ELDs. Advanced lung cancer is one of the most deadly diseases, with a high symptom burden, usually requiring a high level of care and therapy $[11,12]$.

In Flanders and the Netherlands, it has been shown that the practice of euthanasia is relatively rare when considering all deaths $1.9 \%$ in Flanders in 2007 and $1.7 \%$ in the Netherlands in 2005) and more prevalent in deaths caused by cancer $(5.6 \%$ in Flanders and $5.1 \%$ in the Netherlands) $[2,10]$. Little is known, however, about the processes that lead to euthanasia, more specifically about the number of patients who express a wish for euthanasia to the physician, whether this is an explicit and repeated request and whether it leads to euthanasia.
AFFILIATIONS

*End-of-Life Care Research group, Ghent University and Vrije Universiteit Brussel,

${ }^{+}$Dept of Medical Oncology, University Hospital of Brussels, Brussels,

\#Heymans Institute for Pharmacology, Ghent University, 'Bioethics Institute Ghent, Ghent University, Ghent,

${ }^{\S}$ Dept of Pulmonary Medicine, University Hospital of Antwerp, Edegem,

${ }^{f}$ Dept of Pulmonary Medicine, ZNA Middelheim Hospital, Antwerp,

${ }^{* *}$ Dept of Pulmonary Medicine, Hospital Sint-Augustinus, Wilrijk, Belgium.

\#\#Dept of Public and Occupational Health, EMGO Institute for Health and Care Research, VU University Medical Centre, Amsterdam, the Netherlands.

"EOLIC consortium members and their affiliations can be found in the Acknowledgements section.

\section{CORRESPONDENCE}

K. Pardon

End-of-life Care Research group

Ghent University and Vrije

Universiteit Brussel

Laarbeeklaan 103

1090 Brussels

Belgium

E-mail: koen.pardon@vub.ac.be

Received:

Oct 192011

Accepted after revision:

Jan 172012

First published online:

April 202012 
Therefore, this study aims to examine the relationship between euthanasia wishes, euthanasia requests and euthanasia practices in a sample of advanced lung cancer patients in Flanders and the incidence of euthanasia and other ELDs among these patients. It is interesting to study ELDs in Flanders: it is one of the first European countries that accepted a law on euthanasia and it is a country in which great importance is attached to patient autonomy in medical decision-making, e.g. through the law on patient rights of 2002 [13]. International comparative research has shown that such cultural factors as patient autonomy and legal status strongly determine the incidence of certain ELDs such as euthanasia [3, 14].

The research questions were: 1) How many patients with advanced lung cancer wish and request euthanasia, and how often is their request implemented? 2) What characterises the patients who choose euthanasia? 3) What is the incidence of euthanasia and other ELDs among patients with advanced lung cancer?

\section{METHODS}

For the purpose of analysis in this paper, we selected patients who were included in a previous longitudinal interview study [15]. Patients conformed to the following inclusion criteria: a recent initial diagnosis of nonsmall cell lung cancer (NSCLC) stage IIIb or IV, 18 yrs or older, Dutch speaking and physically and psychologically able to participate in the study. The patients were recruited consecutively during one year by pulmonologists and oncologists in 13 hospitals in Flanders. We asked the pulmonologist or oncologist and the general practitioner (GP) of the patient to fill in an after-death questionnaire for those patients who died within 18 months of inclusion in the study.

\section{Measurements}

Inclusion form

At inclusion of the patient in the longitudinal interview study, socio-demographic and clinical characteristics were collected including age, sex, educational level, whether the patient lived with a partner, intention of treatment, comorbidity (Charlson's Comorbidity Index $[16,17])$, whether the patient had a GP and how frequent the contact with the GP was (see online supplementary material).

\section{After death questionnaire}

In the after death questionnaire (see online supplementary material) to be filled in by the treating pulmonologist or oncologist and the GP, the physicians were asked whether the patient had ever expressed a wish for them to administer drugs with the explicit intention of hastening death (we deliberately used a descriptive definition of euthanasia). Then the physician was asked whether explicit and repeated requests had been made. Finally, we measured the occurrence of ELDs, including euthanasia, and the practice of continuous deep sedation until death. ELDs studied were: withholding or withdrawing potentially life-prolonging treatment, intensified alleviation of symptoms and physician assisted death (euthanasia, physician assisted suicide and ending of life without the patient's explicit request). For the practice of continuous deep sedation until death, we asked whether the patient had been deeply sedated until death with or without the artificial administration of food or fluid. The wording of the questions and classification of practices were identical to previous nationwide incidence studies [1,2].
In a separate section of the questionnaire, characteristics of the patient and of death were measured: performance status in the last week before death (ECOG, Eastern Cooperative Oncology Group [18]), whether the patient had died suddenly and unexpectedly, place of death (home, hospital, nursing home or hospice), and quality of death according to the physician (10point Likert-scale from bad to good).

\section{Ethical aspects}

All patients were asked for informed consent to enter the study, and this was renewed at each interview. The protocol was approved by the Ethics Committees of all participating hospitals. A list of the participating hospitals can be found in the Acknowledgements section.

\section{Statistical analysis}

To compare the characteristics of those patients who had expressed a wish for euthanasia with those who had not and to compare the characteristics of those who died after euthanasia and those who did not, the Mann-Whitney U or Fisher's exact test was used; significance was set at $\mathrm{p}<0.05$.

\section{RESULTS}

Pulmonologists and oncologists of the participating hospitals screened 291 patients with a recent initial diagnosis of NSCLC, stage IIIb or IV. 95 patients did not meet the inclusion criteria: 45 patients were physically unable to participate, 34 were psychologically unable to participate, 12 were non-Dutch speaking and four had a combination of the former reasons. With regard to exclusion due to psychological problems: the following problems were mentioned: low IQ (eight patients), psychiatric disorder (12 patients), high anxiety (seven patients), personality disorder (four patients) and total denial of their medical condition (three patients). Of the 196 patients who met the inclusion criteria, 152 were included in the study: 36 patients refused participation and eight were excluded by the specialist (e.g. because they participated in another study). The included patients did not significantly differ with regard to age and sex from the patients who refused participation or were excluded even though they fitted the inclusion criteria, but they had a higher performance status $(p=0.006)$ and mean estimated life expectancy ( 10.3 versus 8.3 months since diagnosis, $p=0.014$ ). Of the 152 patients who agreed to participate, 115 died within 18 months from diagnosis. Finally, for 105 patients, a valid after death questionnaire was returned from the treating physician or physicians. The response rate of specialists was $91.3 \%$ and of GPs $54.8 \%$ (fig. 1).

\section{Characteristics of the studied patients}

The characteristics of the studied patients are shown in table 1.

The mean \pm SD age of the studied patients at inclusion was $64.6 \pm 10.6 \mathrm{yrs} ; 87(82.9 \%)$ patients were male and $76(74.5 \%)$ had a partner. The treatment patients received at inclusion had a life-prolonging intent in three-quarters and a palliative intent in one-quarter. Most received chemotherapy.

In the last week before death $70(72.2 \%)$ patients were completely disabled according to the ECOG performance-scale. 73 $(70.9 \%)$ patients died in the hospital where they were receiving treatment, $15(14.6 \%)$ died under GP care, and 15 (14.6\%) died elsewhere $e . g$. in a hospice. 


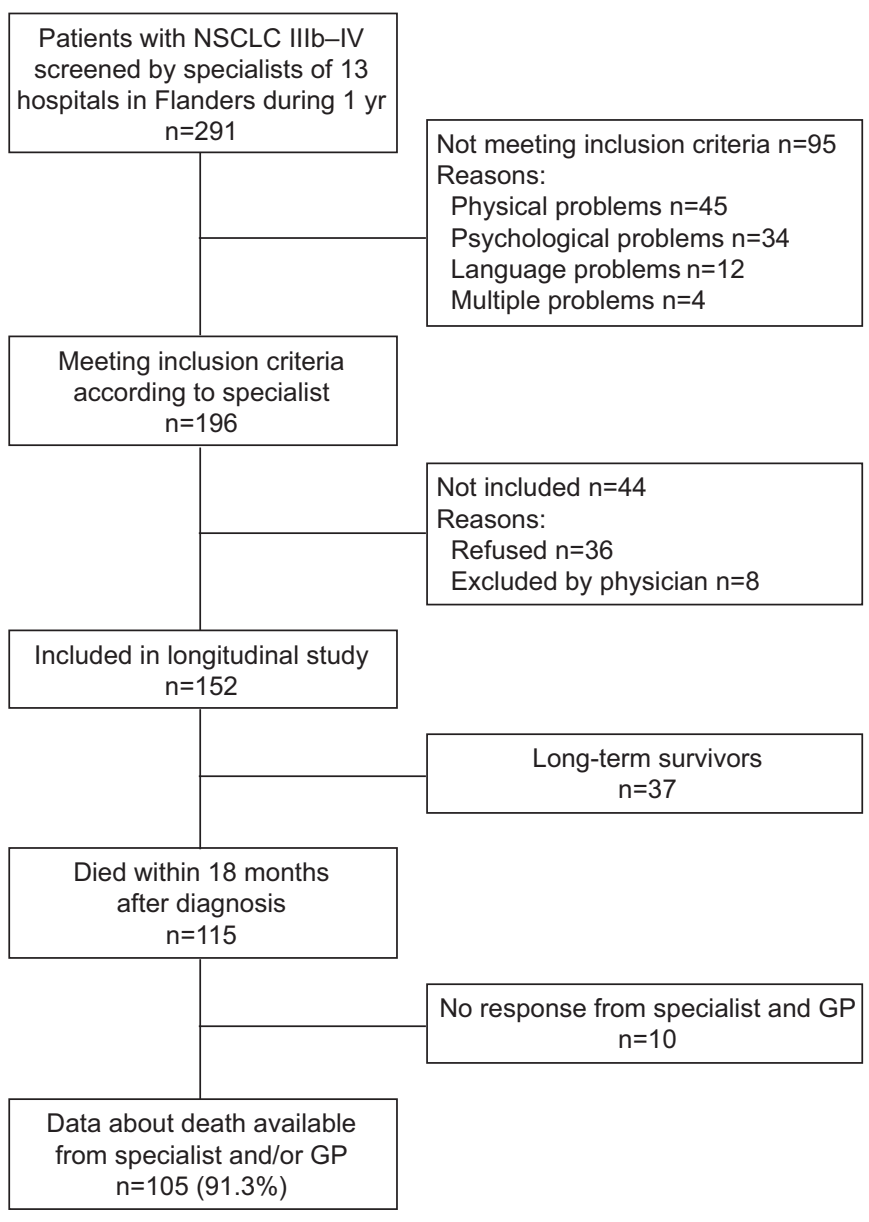

FIGURE 1. Selection of nonsmall cell lung cancer (NSCLC) IIIb-IV patients for study. GP: general practitioner.

\section{Euthanasia: expressed wish, request and implementation of request}

Euthanasia in advanced lung cancer patients, wishes, request and implementations are shown in figure 2.

According to the specialist and/or GP, 21 (20.0\%) out of of 105 advanced lung cancer patients who died within 18 months of diagnosis had expressed a wish for euthanasia. Specialist and GP did not always agree on the existence of a wish. Of the 13 patients with a euthanasia wish for which both specialist and GP had filled in the questionnaire, six patients were reported to have a wish by both physicians, and seven only by one physician (four specialists and three GPs reported a wish expressed, while their colleague reported that no such wish had been expressed).

Of the 21 patients who had expressed a wish for euthanasia, 15 (14.3\% of all patients) had explicitly and repeatedly asked the physician (specialist and/or GP) for euthanasia. Specialist and GP also did not always agree on the existence of an explicit and repeated request. Of the six cases for which both specialist and GP had reported the expression of a euthanasia wish, four patients were reported to have made an explicit and repeated request by both physicians, and two by only one, while the other did not report the making of a request.
Of the 15 patients finally who had explicitly and repeatedly requested euthanasia, 8 (7.6\% of all patients) received euthanasia (fig. 2). None of the patients who had expressed a wish but not an explicit and repeated request (5.7\% of all patients) received euthanasia.

In seven patients euthanasia was not performed despite an explicit and repeated request. Possible reasons for not performing euthanasia could be found in the comments of the physicians. Comments were given in three of the seven cases, each time by the GP (not shown in fig. 2). In one case the patient died before euthanasia could be performed; in another case the patient died in a palliative care unit where he had not repeated his request. In a third case, the patient had asked for euthanasia when suffering became intolerable, but this did not happen according to the physician. In four of seven cases no explanation for not performing euthanasia was given, but we observed that these four patients died in a setting other than that of the reporting physician. In two of these four cases the GP had reported a wish and an explicit and repeated request for euthanasia while the specialist had not, and the patient died in the setting of the specialist. In one case both physicians (specialist and GP) had reported an explicit and repeated request but the patient died in yet another setting. In the last case, only the GP had filled in the questionnaire regarding the death of the patient, but the patient died in a setting other than that of the GP.

We also compared the socio-demographic and clinical characteristics of the seven patients who did not receive euthanasia despite a request with the eight who did: the seven patients lived significantly less long (median of 3 versus 10 months, $p=0.027$ ) and died significantly less often in the hospital $(p=0.041)$.

\section{Characteristics associated with a wish for euthanasia, an explicit and repeated request for euthanasia and implementation of euthanasia}

Expressing a wish, making an explicit and repeated request and receiving euthanasia were not related to age, sex, education and having a partner, or to clinical characteristics such as the frequency of contact with the GP or the treatment hospital (university versus general hospital) (table 1). There were, however, significant positive associations with a palliative treatment goal at inclusion and with not being treated with chemotherapy at inclusion.

There was a significant positive association between the expression of a euthanasia wish or euthanasia and the length of time after diagnosis. Another association concerned the one between receiving euthanasia and a high comorbidity score. There was a positive trend (but not significant) in the association between dying at home (under the care of the GP) and having expressed a wish for euthanasia.

\section{End-of-life decisions other than euthanasia, including continuous deep sedation until death}

End of life decisions other than euthanasia are shown in table 2.

Sudden death struck 11 (10.5\%) patients; 28 (26.6\%) died nonsuddenly without a preceding ELD and 66 (62.9\%) died nonsuddenly with at least one ELD preceding death. Euthanasia was performed in eight patients or $7.6 \%$ of all studied patients. In $15(14.3 \%)$ patients, the ELD consisted of withholding or withdrawing potential life-prolonging treatment (without intent 


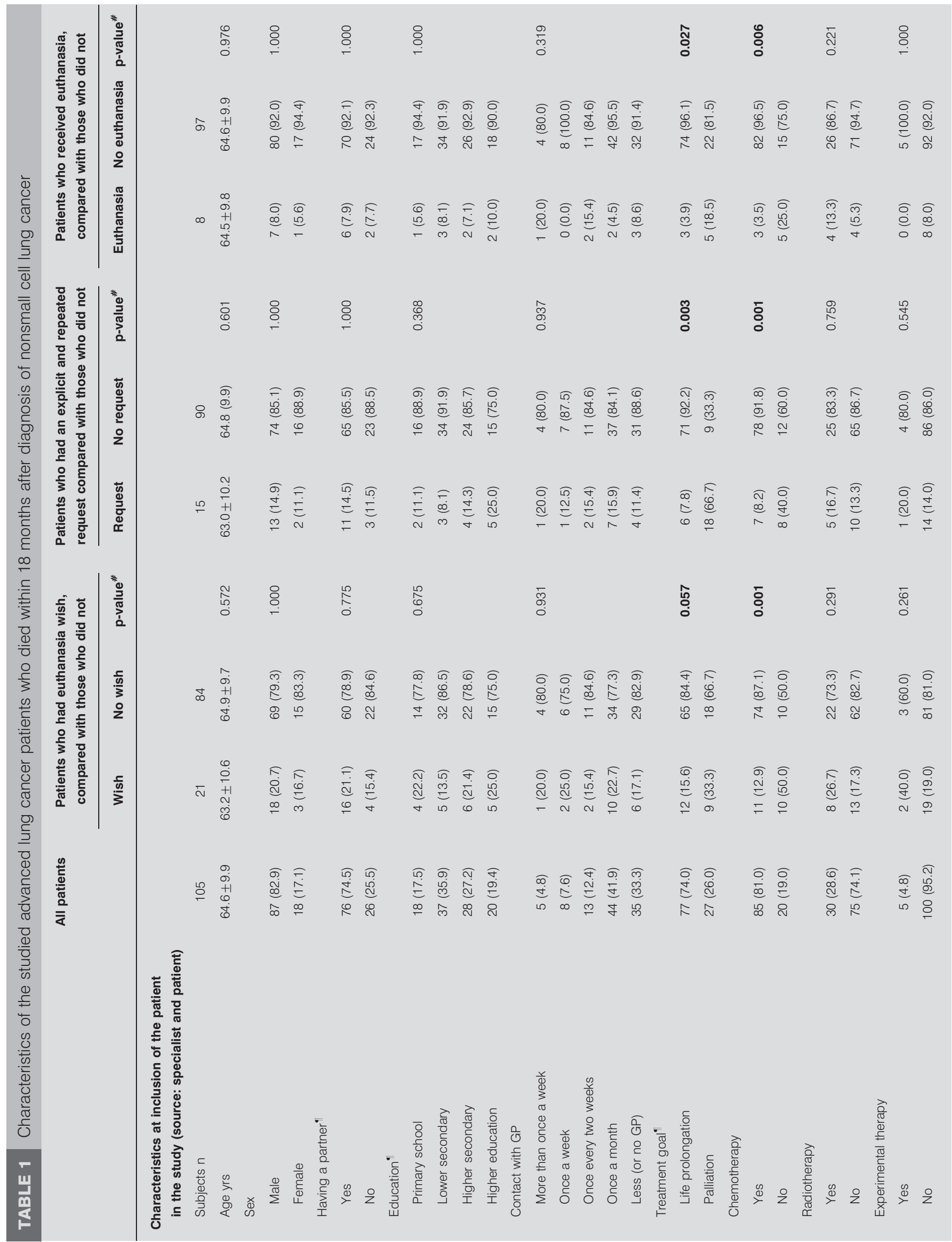




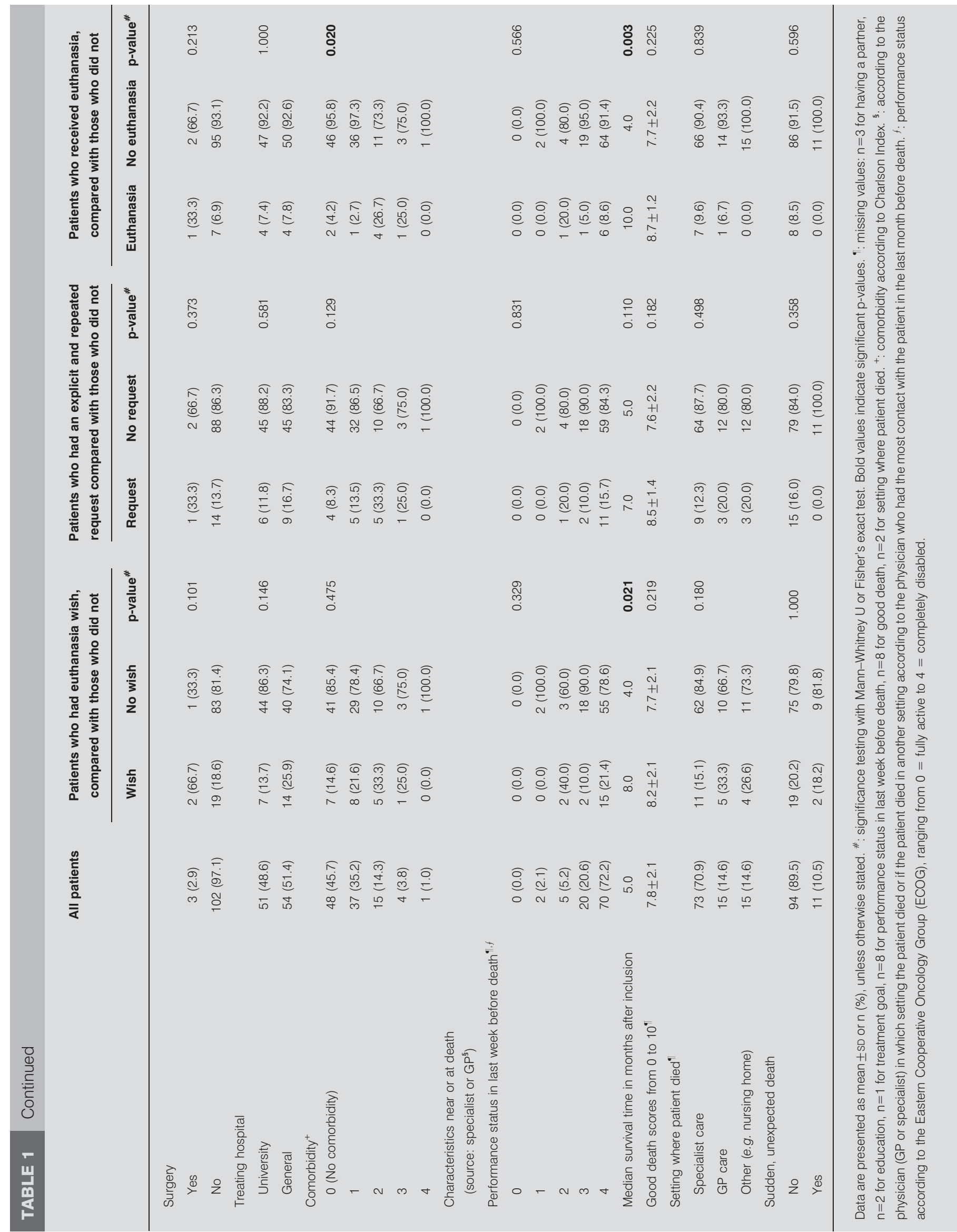




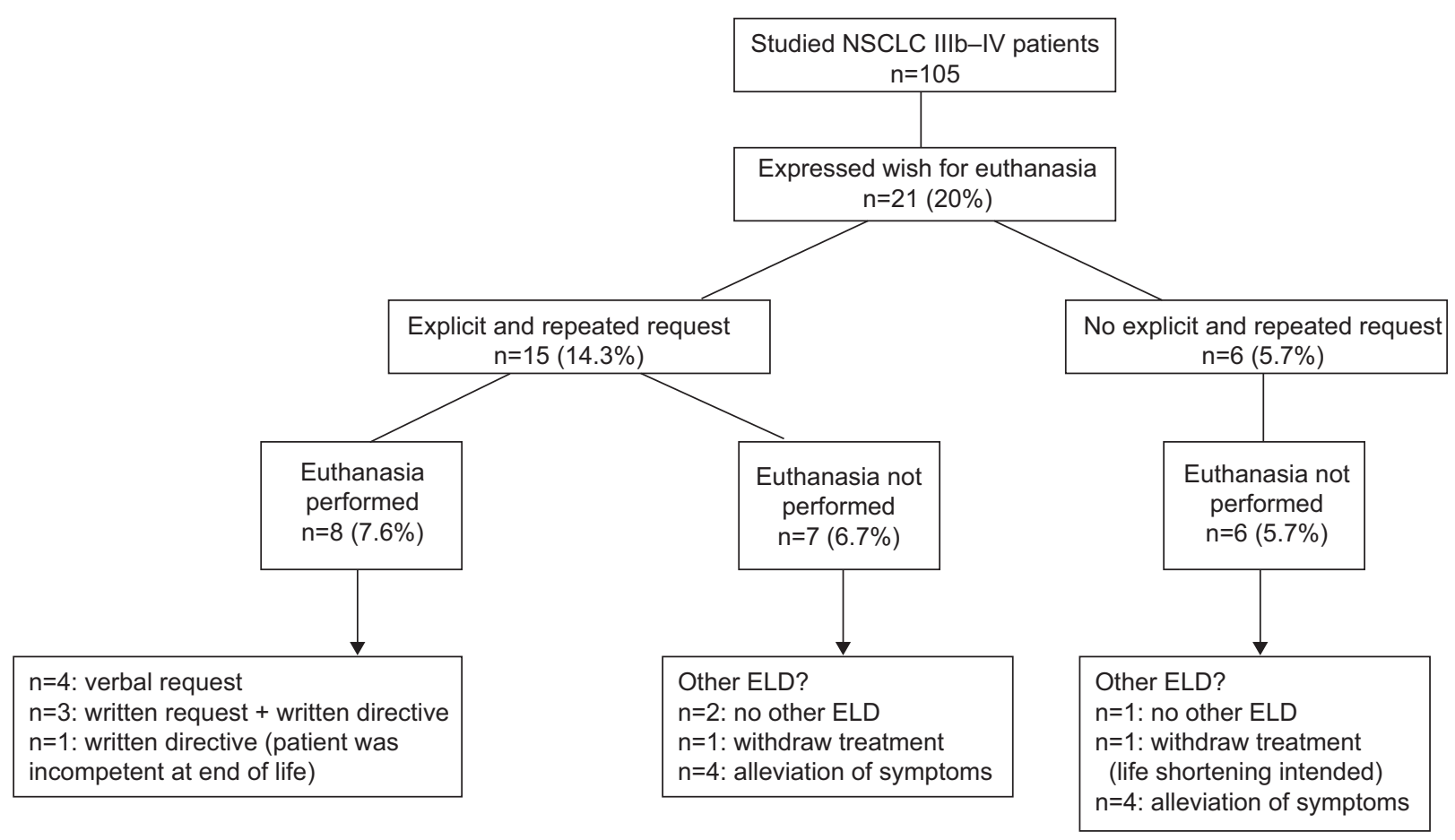

FIGURE 2. Euthanasia in advanced lung cancer patients, according to the treating specialist and/or general practitioner (GP) of the patient. When, if both were applicable, specialist and GP disagreed over presence of wish or explicit and repeated request, presence of wish or explicit and repeated request was entered in the flow chart. NSCLC: nonsmall cell lung cancer; ELD: end-of-life decisions with possible or certain life-shortening effects.

to shorten life in $2.9 \%$ of cases and with intent in $11.4 \%$ ). In 41 $(39.1 \%)$ patients, symptom alleviation was intensified but in most of these cases $(32.4 \%)$ life-shortening was not an additional intention. In two (1.9\%) patients lethal drugs were administered

\begin{tabular}{|c|c|c|}
\hline TABLE 2 & \multicolumn{2}{|c|}{$\begin{array}{l}\text { Frequency of end-of-life decisions in advanced } \\
\text { lung cancer patients who died within } 18 \text { months } \\
\text { after diagnosis of nonsmall cell lung cancer }\end{array}$} \\
\hline \multicolumn{2}{|l|}{ Patients n } & 105 \\
\hline \multicolumn{2}{|c|}{ All deaths preceded by at least one ELD } & $66(62.9)$ \\
\hline \multicolumn{2}{|c|}{$\begin{array}{l}\text { Withholding or withdrawing of potential } \\
\text { life-prolonging treatment }\end{array}$} & $15(14.3)$ \\
\hline \multicolumn{2}{|c|}{ Life-shortening not intended } & $3(2.9)$ \\
\hline \multicolumn{2}{|c|}{ Life-shortening intended } & $12(11.4)$ \\
\hline \multicolumn{2}{|c|}{$\begin{array}{l}\text { Intensifying alleviation of symptoms with } \\
\text { a potential life-shortening effect }\end{array}$} & $41(39.1)$ \\
\hline \multicolumn{2}{|c|}{ Life-shortening not intended } & $34(32.4)$ \\
\hline \multicolumn{2}{|c|}{ Life-shortening additionally intended } & $7(6.7)$ \\
\hline \multicolumn{2}{|c|}{ Physician assisted death } & $10(9.5)$ \\
\hline \multicolumn{2}{|c|}{ Euthanasia } & $8(7.6)$ \\
\hline \multicolumn{2}{|c|}{ Physician assisted suicide } & $0(0.0)$ \\
\hline \multicolumn{2}{|c|}{ Ending of life without patients explicit request } & $2(1.9)$ \\
\hline
\end{tabular}

Data are presented as $n(\%)$, unless otherwise stated. ELD: end-of-life decisions with possible or certain life-shortening effects. ${ }^{*}$ : according to the physician (general practitioner or specialist) in which setting the patient died or if the patient died in another setting according to the physician who had the most contact with the patient in the last month before death. with the explicit intention to shorten the patient life without their explicit request.

Independently of whether or not the aforementioned ELDs had been made, a separate question was asked about the incidence of continuous deep sedation until death. This procedure was applied in 13 patients or $12.4 \%$ of cases (4.8\% with artificial hydration and/or nutrition and $7.6 \%$ without).

\section{DISCUSSION}

This is the first study on euthanasia and the incidence of other end-of-life decisions with possible or certain life-shortening effects in a sample of patients with advanced lung cancer $(n=105)$. One-fifth of the studied advanced lung cancer patients who died within 18 months after diagnosis of fatal lung cancer had expressed a wish for euthanasia according to their GP and/or specialist. In three-quarters of these an explicit and repeated request was made and one-half of these effectively received euthanasia $(7.6 \%$ of all patients). Patients whose treatment goal was exclusively palliative and those who did not receive chemotherapy at inclusion were more likely to express a wish for euthanasia, to make an explicit and repeated request for euthanasia and to receive euthanasia. ELDs other than euthanasia occurred in $55.3 \%$ of cases: intensified alleviation of pain and symptoms occurred in most cases $(39.1 \%)$, followed by non-treatment decisions (14.3\%) and ending of life without patient's explicit request (1.9\%).

A strength of the study was that in contrast with nationwide death certificate studies, the assessment of ELDs was performed by questioning both the treating specialist and the GP, and immediately after the patient had died, thus avoiding 
recall bias [19]. In addition, this study provided data on the qualification of the wish for euthanasia and the care process preceding the performance of euthanasia. Limitations of the study were the relatively small sample size and the limited response rate of the GPs, who were, however, probably less involved in the care of lung cancer patients at the end of life. Another limitation was that this was a physician survey only. A more general remark concerns the generalisability of the study findings: the results of this Flemish study cannot be automatically extrapolated to other European countries that for instance have no law on euthanasia or that place a lower value on the principle of patient autonomy in medical decision making compared with other principles.

A substantial fraction (20\%) of the studied advanced lung cancer patients who died within 18 months after diagnosis had expressed a wish for euthanasia and three-quarters of these patients had also explicitly and repeatedly requested euthanasia. This relationship between expressed wishes and making an explicit and repeated request in our sample is a novel finding. It shows that in most patients an expressed wish for euthanasia reflects determination, and not a reversible state of mind or a spurious reaction to a temporary condition.

Of those patients who had made an explicit and repeated request, around half actually received euthanasia. These percentages are somewhat higher than what was found in a Dutch physician survey of non-sudden cancer deaths in 2005 where $15 \%$ of the cancer patients made an explicit request of euthanasia (the repeated nature of the request was not specified), which were granted in one-third of the cases [20]. In both countries explicit requests for euthanasia were not necessarily honoured. In our study as well as in other Dutch studies the most frequent reasons given for this discrepancy were that the patient withdrew the request or died before the request was granted [21]. However, in our study we observed that in some cases the physician in whose setting the patient died was not aware of a wish, let alone a request because these were expressed to another treating physician. A possible explanation for this discrepancy between physicians was that the patient only told one physician about his euthanasia wish/request and not the other, e.g. because of the delicacy of the topic. Although less likely, it is also possible that the patient told both physicians but that one physician did not register the euthanasia wish/request or interpreted it otherwise, e.g. because of moral objections. Whatever the reasons for these discrepancies are, it is important that the patients tell all their treating physicians clearly what they want at the end of life and that there is an open and regular communication between the treating physicians.

The mere expression of a wish for euthanasia short of an explicit and repeated request did not result in euthanasia. This suggests that the physicians are aware of the stringent legal requirements of due consideration and reiteration of requests for euthanasia, that they comply with them and that they do not perform euthanasia out of these important safeguards [6]. It may also indicate that only determined patients, who are able to verbalise their wishes unambiguously and repeatedly, will have their requests granted.

Expressing a wish for euthanasia, making an explicit or repeated request for euthanasia or receiving euthanasia was independent of a patient's age, sex and education. There was an association with a palliative goal setting in the care plan at diagnosis of the advanced stage of the lung cancer. This may have different explanations. It is possible that these patients were more ill and therefore more inclined to discuss end-of-life issues including euthanasia. It is also likely that a life-prolonging therapeutic objective deflects concerns about the end of life. A related observation was that not receiving chemotherapy following the diagnosis of the advanced lung cancer was also strongly associated with a wish/request/performance of euthanasia. Another finding was that patients who survived longer were more inclined to have a euthanasia wish. This suggests that a long therapeutic relationship may facilitate communication on euthanasia.

Explanations for our finding of an association between an expressed wish for euthanasia and dying at home in the primary care setting can only be speculative and requires further research. One hypothesis is that patients having a preference for euthanasia also prefer to die at home and have more confidence in their GP for carrying out their requests.

Noteworthy is that the incidence of ELDs (including euthanasia) in advanced lung cancer patients is similar to that of all cancer patients in Flanders: at least one ELD was made in $62.9 \%$ and $64.2 \%$ of patients, respectively. The incidences of specific ELDs were also similar to the incidences in Belgian and Dutch cancer populations [22].

To conclude, several recommendations can be made. First, lung cancer physicians should prepare for patients who express a wish for euthanasia because these patients are likely to be determined. Secondly, physicians should be attentive for communication errors: especially in cases of transfer to other care settings where patients' euthanasia requests might not be picked up. Finally, it is important that physicians develop a good relationship with their patients and are open for discussions about palliative care in order to facilitate ELD discussions with their patients.

\section{SUPPORT STATEMENT}

This study was funded by the Fund for Scientific Research in Flanders, Belgium (Project No. FWO/AL336), the Research Council of the Vrije Universiteit Brussel (Project No. HOA2 and OZR1218) and the AstraZeneca Foundation. The sponsors had no role in the design and conduct of the study; in the collection, management, analysis, and interpretation of the data; or in the preparation, review, and approval of the manuscript.

\section{STATEMENT OF INTEREST}

A statement of interest for J.L. Bernheim can be found at www.erj. ersjournals.com/site/misc/statements.xhtml

\section{ACKNOWLEDGEMENTS}

This EOLIC study on End-Of-Life Information and Communication was conducted in collaboration with a consortium of physicians who all recruited advanced lung cancer patients for inclusion in this study: D. Ommeslag (Hospital Sint-Lucas, Ghent, Belgium), R. Devogelaere (Hospital Damiaan, Oostende, Belgium), J. Van Meerbeeck (University Hospital of Ghent, Ghent, Belgium), J. Lamont (Hospital Maria Middelares, Ghent, Belgium), A. Lefebure (ZNA Sint Erasmus Hospital, Borgerhout, Belgium), L. Van Moorter (City Hospital Aalst, Aalst, Belgium), W. Elinck (Hospital Jan Palfijn, Ghent, Belgium), C. Van Schaardenburg (ZNA Jan Palfijn Hospital, Merksem, Belgium), A. Janssens (University Hospital of Antwerp, Edegem, Belgium), E. Potvin (Hospital Sint-Augustinus, Wilrijk, Belgium), A. Debrock (Hospital Sint-Augustinus, 
Wilrijk, Belgium), D. Verresen (Hospital Sint-Augustinus, Wilrijk, Belgium), E. De Droogh (ZNA Middelheim Hospital, Antwerp, Belgium), C. Pollefliet (University Hospital of Antwerp, Edegem, Belgium), K. Vermaelen (University Hospital of Ghent, Ghent, Belgium) and E. van Schoote (University Hospital of Ghent, Ghent, Belgium).

The following hospitals in Belgium participated in this study: ZNA Middelheim Hospital, Antwerp; University Hospital of Brussels, Brussels; University Hospital of Ghent, Ghent; Hospital Maria Middelares, Ghent; Hospital Jan Palfijn, Ghent; ZNA Sint Erasmus Hospital, Borgerhout; Hospital Sint-Lucas, Ghent; City Hospital Aalst, Aalst; ZNA Jan Palfijn Hospital, Merksem; Hospital Damiaan, Oostende; Hospital Sint-Augustinus, Wilrijk; University Hospital of Antwerp, Edegem; and Hospital Sint-Elisabeth, Turnhout.

We thank C. Pauwels-Delanghe (data manager for the EOLIC-study of the End-of-Life Care Research group of the Ghent University and Vrije Universiteit Brussel), E. Michiels (general practitioner and former researcher of the End-of-Life Care Research group of the Ghent University and Vrije Universiteit Brussel), J. Ruthven (English editor) and all the patients, caregivers and interviewers who have contributed to this work.

\section{REFERENCES}

1 Deliens L, Mortier F, Bilsen J, et al. End-of-life decisions in medical practice in Flanders, Belgium: a nationwide survey. Lancet 2000; 356: 1806-1811.

2 Bilsen J, Cohen J, Chambaere K, et al. Medical end-of-life practices under the euthanasia law in Belgium. N Engl J Med 2009; 361: 1119-1121.

3 van der Heide A, Deliens L, Faisst K, et al. End-of-life decisionmaking in six European countries: descriptive study. Lancet 2003; 362: 345-350.

4 Emanuel EJ. Euthanasia and physician-assisted suicide: a review of the empirical data from the United States. Arch Intern Med 2002; 162: 142-152.

5 Kuhse H, Singer P, Baume P, et al. End-of-life decisions in Australian medical practice. Med J Aust 1997; 166: 191-196.

6 Wet betreffende euthanasie 28 mei 2002. Belgisch Staatsblad 22 juni 2002. [Law concerning euthanasia May 28, 2002. Belgian official collection of the Laws June 22, 2002] (in Dutch).

7 Wet toetsing levensbeëindiging op verzoek en hulp bij zelfdoding 1 april, 2002. [Termination of Life on Request and Assisted Suicide (Review Procedures) Act April 1, 2002] (in Dutch).

8 Loi du 16 mars 2009 sur l'euthanasie et l'assistance au suicide [Law of March 16, 2009 on euthanasia and assisted-suicide]. (in French).
9 Bilsen J, Vander Stichele R, Broeckaert B, et al. Changes in medical end-of-life practices during the legalization process of euthanasia in Belgium. Soc Sci Med 2007; 65: 803-808.

10 van der Heide A, Onwuteaka-Philipsen BD, Rurup ML, et al. Endof-life practices in the Netherlands under the Euthanasia Act. N Engl J Med 2007; 356: 1957-1965.

11 Smith W, Khuri FR. The care of the lung cancer patient in the 21st century: a new age. Semin Oncol 2004; 31: 11-15.

12 Zabora J, BrintzenhofeSzoc K, Curbow B, et al. The prevalence of psychological distress by cancer site. Psychooncology 2001; 10: 19-28.

13 Wet betreffende de patiëntenrechten 22 augustus 2002. Belgisch Staatsblad 26 september 2002 [Law concerning patient rights August 22, 2002. Belgian official collection of the Laws September 26, 2002] (in Dutch).

14 Cohen J, Marcoux I, Bilsen J, et al. European public acceptance of euthanasia: socio-demographic and cultural factors associated with the acceptance of euthanasia in 33 European countries. Soc Sci Med 2006; 63: 743-756.

15 Pardon K, Deschepper R, Vander Stichele R, et al. Preferences of advanced lung cancer patients for patient-centred information and decision-making: a prospective multicentre study in 13 hospitals in Belgium. Patient Educ Couns 2009; 77: 421-429.

16 Charlson ME, Pompei P, Ales KL, et al. A new method of classifying prognostic comorbidity in longitudinal studies: development and validation. J Chronic Dis 1987; 40: 373-383.

17 Extermann M. Measuring comorbidity in older cancer patients. Eur J Cancer 2000; 36: 453-471.

18 Oken MM, Creech RH, Tormey DC, et al. Toxicity and response criteria of the Eastern Cooperative Oncology Group. Am J Clin Oncol 1982; 5: 649-655.

19 Chambaere K, Bilsen J, Cohen J, et al. A post-mortem survey on end-of-life decisions using a representative sample of death certificates in Flanders, Belgium: research protocol. BMC Public Health 2008; 8: 299.

20 Onwuteaka-Philipsen BD, Rurup ML, Pasman HR, et al. The last phase of life: who requests and who receives euthanasia or physician-assisted suicide? Med Care 2010; 48: 596-603.

21 Jansen-van der Weide MC, Onwuteaka-Philipsen BD, Van Der WG. Granted, undecided, withdrawn, and refused requests for euthanasia and physician-assisted suicide. Arch Intern Med 2005; 165: 1698-1704.

22 Chambaere K, Bilsen J, Cohen J, et al. Trends in medical end-of-life decision making in Flanders, Belgium 1998-2001-2007. Med Decis Making 2011; 31: 500-510. 